\title{
Is it Time to Shift to Total Thyroidectomy for Benign Thyroid Disease: An Analysis of 77 Redo Thyroidectomies
}

\author{
Ragahvendra G Prasad
}

\section{ABSTRACT}

Aims and objectives: To analyze redo thyroidectomies so as to get a possible answer to the controversy surrounding thyroidectomy for benign disease.

Materials and methods: This is a retrospective observational cohort. From 1996 to 2010, a total 77 cases of redo thyroidectomies were performed. The data of all patients in the department were maintained on a self developed MS access-based software. The data of redo thyroidectomies were reviewed. These patients were from five districts of Andhra Pradesh, 42 were women and 35 men, 51 underwent subtotal thyroidectomy, 21 had hemithyroidectomy and 5 patients had excision procedure; all were benign. The condition varied from multinodular goiter (MNG) and solitary nodule to follicular neoplasm. There were 44 right-sided, and 43 left-sided surgeries. Recurrence occurred in seven in less than 1 year, in 49 in less than 5 years, in 11 of them in less than 10 years and 10 had recurrence after 10 years. A total thyroidectomy was performed in all. Seventy-five had benign disease. Two had suspected neoplasm; one papillary and one Hurthle cell. One patient had transient recurrent laryngeal nerve palsy.

Results: Seventy-seven redo surgeries for benign thyroid disease were performed. The high rate of referrals for recurrence probably suggests inadequacy of subtotal and hemithyroidectomies for benign thyroid diseases.

Conclusion: The present series of 77 redo thyroidectomies clearly suggests inadequacy of initial subtotal thyroidectomy. Evidence-based analysis of complication rates and surgical feasibility supports total thyroidectomy as the complete safe, scientifically acceptable choice of primary surgical treatment for benign thyroid disease.

Keywords: Benign goiters, Parathyroid sparing PBC surface thyroidectomy, Total thyroidectomy.

How to cite this article: Prasad RG. Is it Time to Shift to Total Thyroidectomy for Benign Thyroid Disease: An Analysis of 77 Redo Thyroidectomies. Int J Phonosurg Laryngol 2015;5(1):4-6.

Source of support: Nil

Conflict of interest: None

Professor

Department of Pediatric Surgery, Deccan College of Medical Sciences, Hyderabad, Telangana, India

Corresponding Author: Ragahvendra G Prasad, Professor Department of Pediatric Surgery, Deccan College of Medical Sciences, Hyderabad, Telangana, India, Phone: 09849096145 e-mail: grprasad22@gmail.com

\section{INTRODUCTION}

Treatment of thyroid goiters had been primarily centered around surgical excision..$^{1-3}$ Subtotal thyroidectomy was and continues to be most commonly performed surgical procedure for most of goiters. Total thyroidectomy was performed as the primary procedure in malignant tumors and as completion thyroidectomy whenever histopathology suggested malignancy.,

Injury to parathyroids and consequent hypoparathyroidism and injury to recurrent laryngeal nerve were the two most important reasons cited to prefer subtotal thyroidectomy. However, these days, parathyroid conservation, preservation and implantation have all reduced postoperative hypoparathyroidism. Total thyroidectomy is much safer and should be the primary surgery for benign thyroid disease. ${ }^{4-6}$

\section{MATERIALS AND METHODS}

All the patients were referred for redo thyroidectomies. All patients belonged to five districts of Andhra Pradesh, of which, one is endemic for goiter. All records were retrieved from the data stored in self-developed MS access-based software in use from 1996. This was the source of data, with software so tightly structured that inadequate data would be rejected. The records of redo thyroidectomy over the last 15 years were analyzed with regards to the following:

- The primary cause of goiter

- Type of procedure done

- Pathological outcome.

\section{RESULTS}

Table 1 shows the age-gender division. Forty-two (55\%) were women, $35(45 \%)$ were men. Table 2 shows the reason for which previous hemi or partial thyroidectomy was performed. Fifty-one (66\%) out of 77 underwent subtotal thyroidectomy, 21 (27\%) had hemithyroidectomy, 5 (7\%) had local excision as the treatment. All the 77 were reported to be benign on histology. The native condition varied from euthyroid multinodular goiter, solitary nodule, toxic nodule and follicular neoplasm. There was no side preponderance. Forty-four (57\%) were right-sided surgeries, 33 (43\%) had left-sided surgeries. Table 3 shows side and disease distribution. 
Is it Time to Shift to Total Thyroidectomy for Benign Thyroid Disease: An Analysis of 77 Redo Thyroidectomies

Table 1: Gender and age-wise distribution

\begin{tabular}{lllll}
\hline Gender & $<30$ years & $31-50$ years & $>50$ years & Total \\
\hline Males & 13 & 15 & 07 & 35 \\
Females & 07 & 26 & 09 & 42 \\
\hline Total & 20 & 41 & 16 & 77
\end{tabular}

Table 2: Previous procedure

\begin{tabular}{ll}
\hline Procedure & Number of cases \\
\hline Subtotal thyroidectomy & $37(66 \%)$ \\
Hemithyroidectomy & $21(27 \%)$ \\
Local excision & $05(7 \%)$ \\
\hline Total & 77 \\
\hline
\end{tabular}

Table 3: Side and disease distribution

\begin{tabular}{llllllll}
\hline Side & MNG & $\begin{array}{l}\text { Colloid } \\
\text { goiter }\end{array}$ & Solitary & $\begin{array}{l}\text { Toxic } \\
\text { nodule }\end{array}$ & $\begin{array}{l}\text { Follicular } \\
\text { neoplasm }\end{array}$ & Adenoma & Total \\
\hline Right & 10 & 05 & 04 & 03 & 02 & 07 & 31 \\
Left & 11 & 04 & 07 & 02 & 01 & 08 & 33 \\
Bilateral & 11 & 02 & 00 & 00 & 00 & 00 & 13 \\
\hline Total & 32 & 11 & 11 & 05 & 03 & 15 & 77 \\
\hline
\end{tabular}

Table 4 shows interval period of recurrence after first surgery. Recurrence occurred in $7(9 \%)$ cases in less than 1 year, 49 (64\%) cases had recurrence under 5 years and $11(10 \%)$ were under 10 years. Ten $(13 \%)$ had recurrence after 10 years.

Total thyroidectomy was performed in all. Out of 77 cases, 75 had benign disease. Two had suspected neoplasm; one papillary and one Hurthle cell. One patient had recurrent laryngeal nerve palsy.

\section{DISCUSSION}

Incidence of goiter in some parts of Andhra Pradesh is very high. Most cases are due to deficiency of iodine and some are reported secondary to consumption of particular type of fish. The chosen procedure for the treatment of benign thyroid disease has been subtotal thyroidectomy. ${ }^{1-3}$ Total thyroidectomy was considered only where malignancy was suggested on histology. ${ }^{1-4}$ Most of patients from the present series too were from a cluster of endemic districts. Postoperative parathyroid and recurrent laryngeal nerve injury were two important reasons to choose subtotal thyroidectomy. ${ }^{5}$

Total thyroidectomy is still not the favored primary surgical procedure for benign thyroid disease. Review of 77 redo thyroidectomy clearly showed that the earlier choice of subtotal thyroidectomy was an insufficient surgical treatment for benign diseases.

Theoretically, the same factors responsible for goitrogenesis continued to influence the remnant thyroid

Table 4: Interval of recurrence

\begin{tabular}{ll}
\hline Period & Number of cases \\
\hline$<1$ year & $07(9 \%)$ \\
$1-5$ years & $49(64 \%)$ \\
$6-10$ years & $11(14 \%)$ \\
$>10$ years & $10(13 \%)$ \\
\hline
\end{tabular}

tissue and contribute to recurrence of goiter. Bellantone $\mathrm{R}$ et al $2002^{5}$ also suggested this cause for recurrence.

Total thyroidectomy for benign thyroid disease has off late being considered as the surgical option..$^{5-9}$ Redo thyroidectomies pose a higher chance of injury to the recurrent laryngeal nerve and postoperative complications. $^{8}$

Hence, total thyroidectomy is being proposed as the choice of primary surgical procedure. Only one of the 77 redo thyroidectomies had a temporary recurrent laryngeal nerve palsy suggesting total thyroidectomy is safe.

Survey of literature Bellantone R et al 2002, ${ }^{5}$ Loannis V et al 2013, ${ }^{8}$ Efremidou El et al 2008, ${ }^{10}$ Guraya and Auzobybi, $2006^{9}$ and Ata ul L et al $2011^{11}$ also confirmed the safety of total thyroidectomy.

In addition, capsule dissection avoids parathyroid ischemia and possibly avoids surgical injury to recurrent laryngeal nerve. ${ }^{12}$ The latter half of the present series was done using surface thyroidectomy technique.

An attempt was made by Gaurav and Vivek Agarwal to search for evidence in favor of total thyroidectomies for benign disease. Consistent level 2 to 4 evidence pointed at recurrence upto $50 \% .{ }^{13}$ This evidence also showed the permanent complications rate of subtotal thyroidectomy and total thyroidectomy to be the same. Hence, Gaurav and Vivek suggested a grade-B recommendation that subtotal thyroidectomy has significant recurrence of Goiter, either leaving a small leaf undetected or unsuspected malignancy incompletely treated and has similar complication rate as total thyroidectomy.

Permanent recurrent laryngeal nerve palsy and hypo parathyroidism was also below $2 \%$ and was given grade- $\mathrm{C}$ recommendation. Hence, this evidence based analysis suggested by Gaurav and Vivek ${ }^{13}$ also supports the present series that total thyroidectomy is technically acceptable, scientifically sound choice of primary surgical option to treatment of benign thyroid disease. 


\section{CONCLUSION}

The present series of 77 redo thyroidectomies clearly suggests the inadequacy of initial subtotal thyroidectomy. The complication rate and surgical feasibility evidence based analysis support total thyroidectomy as the complete safe, scientifically acceptable choice of primary surgical treatment for primary surgical treatment for benign thyroid disease.

\section{REFERENCES}

1. Norman SW, Christopher JKB, Ronan P. Bailey and love's short practice of surgery, 26th ed. 2103 p. 741-771.

2. Charles FB, Dana KA, Timothy RB, David LD, et al. Schwartz's Principles of Surgery, 9th ed. 2010. p. 1344-1369.

3. Gough IR, Wikinson D. Total thyroidectomy for management of thyroid disease. World J Surg 2000;24(8):962-965.

4. Serdar T, Ismail B, Yasemin S, Faith T, Tamik T. The change in surgical practice from subtotal to near total or total thyroidectomy in treatment of patients with benign multinodular -goiter. World J Surg 2009;33(3):400-405.

5. Bellantone R, Lombardi CP, Boosolam, Boscherini M, Decrea C, Alesina P, Traini E, Princi P, Rafelli M. Total thyroidectomy for management of benign thyroid disease: review of 526 cases. World J Surg 2002;26(12):1468-1471.
6. Liu Q, Djuricin G, Prinza. Total thyroidectomy for benign thyroid disease. Surg 1998;123(1):2-7.

7. Ho TW, Shaheen AA, Dixon E, Harvey A. Utilization of thyroidectomy for benign disease in the united states: a 15-year population based study. Am J Surg 2011;201(5): 570-574.

8. Loannis V, Alik T, Nikolas A, Fotios N, et al. Total thyroidectomy as the single surgical option for benign and malignant thyroid disease: a surgical challenge. Arch Med Sci 2013; 9(1):74-78.

9. Guraya SY, Auzobybi AH. Total and near total thyroidectomy is better than subtotal thyroidectomy for the treatment of bilateral multinodular goiter: a prospective analysis. BJMMR 2006;1(1):1-6.

10. Efremidou El, Papageorgious MS, Lirtazopoulus N, Manolas KJ. The efficacy and safety of total thyroidectomy in the management of benign thyroid disease: a review of 932 cases. Can J Surg 2009;52(1):39.

11. Ata ul L, Muhammed S, Muhammed Y, Sarwat B, Junaid M. Total thyroidectomy as preferred option for benign diseaseour experience of 152 cases. JUMDC 2012;3(1):16-21.

12. Abdelshaheed F. Total thyroidectomy for clinically benign thyroid disease a preferred option with capsular dissection technique. EJS 2006;25(3):149-154.

13. Agarwal G, Aggarwal V. Is total thyroidectomy the surgical procedure of choice for benign multinodular goiter? An evidence based review. World J Surg 2008;32(3):1313-1324. 